\title{
Hospital admissions for vitamin D related conditions and subsequent immune-mediated disease: record-linkage studies
}

\author{
Sreeram V Ramagopalan ${ }^{1,2}$, Raph Goldacre ${ }^{3}$, Giulio Disanto ${ }^{1}$, Gavin Giovannoni ${ }^{2}$ and Michael J Goldacre ${ }^{3 *}$
}

\begin{abstract}
Background: Previous studies have suggested that there may be an association between vitamin D deficiency and the risk of developing immune-mediated diseases.

Methods: We analyzed a database of linked statistical records of hospital admissions and death registrations for the whole of England (from 1999 to 2011). Rate ratios for immune-mediated disease were determined, comparing vitamin D deficient cohorts (individuals admitted for vitamin D deficiency or markers of vitamin D deficiency) with comparison cohorts.

Results: After hospital admission for either vitamin D deficiency, osteomalacia or rickets, there were significantly elevated rates of Addison's disease, ankylosing spondylitis, autoimmune hemolytic anemia, chronic active hepatitis, celiac disease, Crohn's disease, diabetes mellitus, pemphigoid, pernicious anemia, primary biliary cirrhosis, rheumatoid arthritis, Sjogren's syndrome, systemic lupus erythematosus, thyrotoxicosis, and significantly reduced risks for asthma and myxoedema.

Conclusions: This study shows that patients with vitamin D deficiency may have an increased risk of developing some immune-mediated diseases, although we cannot rule out reverse causality or confounding. Further study of these associations is warranted and these data may aid further public health studies.
\end{abstract}

Keywords: Vitamin D, Immune disease, Hospital episode statistics

\section{Background}

Immune-mediated diseases cumulatively represent one of the most common chronic disease groups in medicine today, affecting approximately $10 \%$ of first world populations [1]. There is substantial evidence in support of these disorders being determined by both genetic and environmental factors. One candidate environmental risk factor implicated in immune-mediated disease susceptibility is vitamin D deficiency [2-4].

Historically, vitamin D was thought to play a restricted role in calcium homeostasis; however, a wealth of studies now suggests that it exerts more widespread effects $[5,6]$. Functional laboratory studies have shown that vitamin $\mathrm{D}$ can modulate the immune response $[5,6]$ and a

\footnotetext{
*Correspondence: michael.goldacre@dph.ox.ac.uk

${ }^{3}$ Unit of Health-Care Epidemiology, Nuffield Department of Population Health, University of Oxford, Oxford, UK

Full list of author information is available at the end of the article
}

number of epidemiological findings have implicated the involvement of vitamin D deficiency in the risk of developing immune-mediated diseases [2-4]. These include the ecological findings of the prevalence of diseases, such as multiple sclerosis (MS), type 1 diabetes, inflammatory bowel disease, rheumatoid arthritis and Sjogren's syndrome, positively correlating with latitude and reduced ultraviolet radiation exposure (the primary determinant of vitamin D levels) [1]. Further support comes from studies showing low serum vitamin $\mathrm{D}$ levels in patients suffering from a wide range of immune disorders, including MS [7], type 1 diabetes [8], systemic lupus erythematosus (SLE) [9] and rheumatoid arthritis [10]. These findings may, however, be biased by reverse causation [11].

To investigate further any association between vitamin $\mathrm{D}$ and immune-mediated disease, we undertook record linkage studies to determine the risk of immune-mediated 
disease in individuals admitted for vitamin D deficiency or a marker of vitamin D deficiency (rickets or osteomalacia) using an English national linked Hospital Episode Statistics (HES) dataset.

\section{Methods \\ Population and data}

We used a linked English national dataset of hospital admissions (Hospital Episode Statistics (HES)) and mortality. HES data are records of hospital care that are compiled for every episode of day case care or hospital admission in all English National Health Service (NHS) hospitals, and were supplied by the English national Information Centre for Health and Social Care. The mortality data were derived from death certificates and were supplied by the Office for National Statistics. The linked dataset used in this study, in which successive records for each individual were linked together, was constructed by the Oxford record linkage group.

The International Classification of Disease (ICD) codes used for the vitamin $\mathrm{D}$ related conditions were osteomalacia (M83.1, M83.8, M83.9), rickets (E55.0, E64.3) and vitamin D deficiency (E55.9). The ICD codes used for the immune-mediated diseases were Addison's disease (E27.1), ankylosing spondylitis (M45), asthma (J45), autoimmune hemolytic anemia (D59.1), chronic active hepatitis (K73.2), Crohn's disease (K50), celiac disease (K90.0), dermatomyositis (M33.0 to M33.1), diabetes mellitus (E10 to E14), polymyositis (M33.2), Goodpasture's syndrome (M31.0), Hashimoto's thyroiditis (E06.3), idiopathic thrombocytopenia purpura (D69.3), multiple sclerosis (G35), myasthenia gravis (G70.0), myxoedema (E03.8 to E03.9), pemphigus (L10), pemphigoid (L12), pernicious anemia (D51.0), polyarteritis nodosa (M30.0), primary biliary cirrhosis (K74.3), psoriasis (L40), rheumatoid arthritis (M05 to M06), scleroderma (M34), Sjogren's syndrome (M35.0), SLE (M32.1 to M32.9), thyrotoxicosis (E05), and ulcerative colitis (K51). In the analysis of diabetes mellitus, we used hospital admission for diabetes mellitus when the patient was aged under 30 as a proxy for type 1 diabetes, as the type of diabetes is not well recorded in routine hospital statistics. We also confined the analysis of asthma admissions to people aged between the ages of 5 and 54 to reduce potential issues with misclassification of asthmalike respiratory conditions in younger and older people.

The methods of analysis were the same for all vitamin D-related admissions and immune-mediated diseases; we describe the methods for rickets and Crohn's disease as the example. A cohort of people with rickets was constructed for those with a diagnosis of rickets as a reason for hospital care, by identifying the first episode of day case care, or admission, for rickets during the study period. A reference cohort was constructed by identifying the first admission for each individual with various other, mainly minor medical and surgical, conditions (listed in the Table 1 legend), as in previous studies of disease associations [12]. Standard epidemiological practice was followed by selecting a diverse range of conditions rather than relying on a limited range (in case the latter are themselves atypical in their risk of immune-mediated disease) [12]. As a check, we studied the risk of immune-mediated disease in the control conditions within the reference cohort to ensure that the reference cohort did not include control conditions that have atypically high or low immune mediated-disease rates. For some immune-mediated diseases (for example, rheumatoid arthritis), we removed some control conditions (for example, hip/knee replacement) from the reference cohort where we considered that this may otherwise have skewed the findings. For the fairly small number of associations affected by this, we show the adjusted' associations (that is, with some control conditions removed) for these diseases in the main paper; for completeness and comparison, the unadjusted associations are also provided (see below). Anyone with both an 'exposure' disease, for example, Crohn's disease, and a reference cohort condition was included in the exposure cohort and excluded from the reference cohort.

People were included in the rickets or reference cohort if they did not have an admission for an immunemediated disease either before or at the same time as the admission for rickets or the reference condition. The database was then investigated for any subsequent NHS hospital care for, or death from, Crohn's disease in these cohorts. We considered that rates of Crohn's disease in the reference cohort would approximate those in the general population while allowing for migration as data on migration of individuals were not available.

The analysis was performed using a suite of programs developed 'in house' using SAS 9 software (SAS Institute, Cary, NC, USA).

\section{Ethical approval}

The construction and analysis of the datasets were undertaken with the approval of the Central and South Bristol Research Ethics Committee (REC, reference 04/ Q2006/175).

\section{Statistical methods}

Rates of Crohn's disease were calculated based on personyears. Date of entry into each cohort was the date of the first admission for rickets, or reference condition, and date of exit was the date of the first record of Crohn's disease, death or the end of data collection (28 February 2011), whichever was the earliest. We first calculated rates for Crohn's disease, stratified and then standardized by age (in five-year age groups), sex, calendar year of first recorded admission, region of residence, and quintile of patients' 
Table 1 Age-distribution of people in exposure cohorts, percentage who were female, and numbers in reference cohort $^{1}$

\begin{tabular}{|c|c|c|c|c|}
\hline Exposure condition & Age at admission & $\begin{array}{l}N \text { in the exposure } \\
\text { cohort (\% of total) }\end{array}$ & $\%$ female & $\begin{array}{l}\text { Number in the } \\
\text { reference cohort }\end{array}$ \\
\hline \multirow{6}{*}{$\begin{array}{l}\text { Rickets, osteomalacia, or vitamin D } \\
\text { deficiency, all combined: }\end{array}$} & $<15$ & $745(7.5)$ & 53.0 & 889,364 \\
\hline & 15 to 44 & $532(24)$ & 72.4 & $2,906,048$ \\
\hline & 45 to 64 & $1,191(26.7)$ & 70.4 & $2,206,093$ \\
\hline & 65 to 74 & $1,356(15.1)$ & 68.9 & $1,198,951$ \\
\hline & $75+$ & $1,697(26.7)$ & 73.1 & $1,403,767$ \\
\hline & All ages & $19,338(100)$ & 70.1 & $8,604,223$ \\
\hline \multirow[t]{6}{*}{ Rickets: } & $<15$ & $494(54.8)$ & 48.9 & 889,495 \\
\hline & 15 to 44 & $73(16.8)$ & 70.4 & $2,907,044$ \\
\hline & 45 to 64 & $32(8.7)$ & 71.0 & $2,207,541$ \\
\hline & 65 to 74 & $29(7)$ & 68.6 & $1,200,051$ \\
\hline & $75+$ & $42(12.7)$ & 78.2 & $1,405,341$ \\
\hline & All ages & $1,228(100)$ & 59.5 & $8,609,472$ \\
\hline \multirow[t]{6}{*}{ Osteomalacia: } & $<15$ & $1(0.1)$ & 0.0 & 889,562 \\
\hline & 15 to 44 & 39 (16.9) & 68.8 & $2,906,823$ \\
\hline & 45 to 64 & $275(30.3)$ & 62.7 & $2,207,108$ \\
\hline & 65 to 74 & $503(20.5)$ & 68.3 & $1,199,703$ \\
\hline & $75+$ & $585(32.2)$ & 76.7 & $1,404,882$ \\
\hline & All ages & $5,191(100)$ & 69.4 & $8,608,078$ \\
\hline \multirow[t]{6}{*}{ Vitamin D deficiency: } & $<15$ & $263(6)$ & 56.8 & 889,428 \\
\hline & 15 to 44 & $436(27.5)$ & 73.5 & $2,906,311$ \\
\hline & 45 to 64 & $911(26.9)$ & 74.0 & $2,206,566$ \\
\hline & 65 to 74 & $847(13.8)$ & 69.5 & $1,199,332$ \\
\hline & $75+$ & 1,107 (25.8) & 71.5 & $1,404,315$ \\
\hline & All ages & $13,260(100)$ & 71.5 & $8,605,952$ \\
\hline
\end{tabular}

${ }^{1}$ The reference cohort consisted of people admitted with the following conditions coded under the Office of Population, Censuses and Surveys (OPCS) code edition 4 for operations and ICD10 code for diagnosis (with equivalent codes used for other coding editions): appendectomy (OPCS4 H01 to H03), adenoidectomy (E20), tonsillectomy (F34 + F36), dilation and curettage (Q10.3 + Q11.4), total hip replacement (W37 to W39), total knee replacement (W40 to W42), squint (ICD10 H49 to H51), cataract (H25), otitis externa/media (H60 to H67), varicose veins (183), hemorrhoids (184), deflected septum, nasal polyp (J33 + J34.2), impacted tooth and other disorders of teeth (K00 to K03), inguinal hernia (K40), in-growing nail, toenail and other diseases of the nails (L60), sebaceous cyst (L72.1), bunion (M20.1), internal derangement of the knee (M23), dislocations, sprains and strains ( $\mathrm{S} 03, \mathrm{~S} 13, \mathrm{~S} 23$, S33, S43, S53, S63, S73, S83, S93), selected limb fractures (S42, $\mathrm{S} 52, \mathrm{S62}, \mathrm{S} 82, \mathrm{S92})$, superficial injury and contusion (S00, S10, S20, S30, S40, S50, S60, S70, S80, S90), contraceptive management (Z30).

${ }^{2}$ The numbers in the reference cohort vary slightly depending on what the exposure condition is. This is because individuals, who otherwise fulfilled the criteria for inclusion in the reference cohort, were removed from the reference cohort if they fulfilled the criteria for inclusion in the exposure cohort (see Methods).

Index of Deprivation score (a standard English measure of socio-economic status). The indirect method of standardization was used, with the combined rickets and reference cohorts as the standard population. We applied the stratum-specific rates in the standard population to the number of people in each stratum in the rickets cohort and then, separately, to those in the same stratum in the reference cohort, to obtain the expected number of people with Crohn's disease in each stratum of the rickets and reference cohort. Observed and expected numbers were then summed across all strata to give totals for all strata combined. Rate ratios were calculated by taking the standardized rate of occurrence of Crohn's disease in the rickets cohort relative to the reference cohort using the formula $\left(\mathrm{O}^{\text {rickets }} / \mathrm{E}^{\text {rickets }}\right) /\left(\mathrm{O}^{\mathrm{ref}} / \mathrm{E}^{\mathrm{ref}}\right)$, where $\mathrm{O}$ and $\mathrm{E}$ are the observed and expected numbers of Crohn's disease cases in the rickets and reference cohorts, respectively. In each table, we only show diseases in which either the observed or expected number, or both were five or more. The confidence interval for the rate ratio of Crohn's and $x^{2}$ statistics for its significance were calculated as described elsewhere [13].

\section{Results}

The number of people in the cohort with vitamin D deficiency was 13,260 (71.5\% female), osteomalacia 5,191 (69.4\% female), and rickets 1,228 (59.5\% female). Age 
distributions are shown in Table 1 . There were more than 8.6 million people in the reference cohort.

There were significantly elevated risks of Addison's disease, ankylosing spondylitis, autoimmune hemolytic anemia, chronic active hepatitis, celiac disease, Crohn's disease, diabetes mellitus, pemphigoid, pernicious anemia, primary biliary cirrhosis, rheumatoid arthritis, Sjogren's syndrome, systemic lupus erythematosus, thyrotoxicosis; and significantly reduced risks for asthma and myxoedema after hospital admission for either vitamin D deficiency, osteomalacia or rickets (Table 2).

There were significantly elevated risks of celiac disease, pernicious anemia and thyrotoxicosis after hospital

Table 2 Rate ratios for immune-mediated diseases following admission for rickets, osteomalacia or vitamin D deficiency, combined

\begin{tabular}{|c|c|c|c|c|}
\hline Disease & 0 & $\mathrm{E}$ & $\mathrm{RR}(95 \% \mathrm{Cl})$ & $P$-value \\
\hline Addison's disease & 21 & 3 & $7.2(4.4$ to 11.0$)$ & $<0.001$ \\
\hline Ankylosing spondylitis ${ }^{1}$ & 16 & 8.2 & 2.0 (1.1 to 3.2$)$ & 0.01 \\
\hline Asthma (aged 5 to 54$)^{2}$ & 150 & 375.5 & $0.4(0.3$ to 0.5$)$ & $<0.001$ \\
\hline Autoimmune hemolytic anemia & 6 & 2.2 & 2.7 (1.0 to 5.9$)$ & 0.03 \\
\hline Chronic active hepatitis & 6 & 1 & $6.2(2.3$ to 13.5$)$ & $<0.001$ \\
\hline Celiac disease ${ }^{3}$ & 78 & 14.3 & 5.5 (4.3 to 6.9$)$ & $<0.001$ \\
\hline Crohn's disease $^{3}$ & 47 & 17.9 & 2.6 (1.9 to 3.5$)$ & $<0.001$ \\
\hline Diabetes mellitus (aged 0 to 29$)^{4}$ & 7 & 1.8 & 3.9 (1.6 to 8.1) & $<0.001$ \\
\hline Hashimoto's & 6 & 2.8 & 2.1 (0.8 to 4.6$)$ & 0.11 \\
\hline Idiopathic thrombocyt. purpura & 11 & 8.3 & 1.3 (0.7 to 2.4$)$ & 0.44 \\
\hline Multiple sclerosis $^{5}$ & 15 & 13.1 & $1.1(0.6$ to 1.9$)$ & 0.7 \\
\hline Myxoedema & 335 & 520.4 & 0.6 (0.6 to 0.7$)$ & $<0.001$ \\
\hline Pemphigoid & 13 & 4.9 & 2.7 (1.4 to 4.5$)$ & 0.001 \\
\hline Pernicious anemia & 60 & 35.7 & 1.7 (1.3 to 2.2$)$ & $<0.001$ \\
\hline Polymyositis & 5 & 1 & $5.1(1.6$ to 11.9$)$ & $<0.001$ \\
\hline Primary biliary cirrhosis & 12 & 4.4 & 2.8 (1.4 to 4.8$)$ & 0.001 \\
\hline Psoriasis & 29 & 44.2 & 0.7 (0.4 to 0.9$)$ & 0.03 \\
\hline Rheumatoid arthritis $^{1}$ & 158 & 126.2 & $1.3(1.1$ to 1.5$)$ & 0.005 \\
\hline Scleroderma & 6 & 3.4 & $1.8(0.7$ to 3.9$)$ & 0.25 \\
\hline Sjogren's syndrome & 20 & 9.4 & 2.1 (1.3 to 3.3$)$ & 0.001 \\
\hline Systemic lupus erythematosus & 33 & 8.1 & 4.1 (2.8 to 5.8$)$ & $<0.001$ \\
\hline Thyrotoxicosis & 100 & 57.7 & 1.7 (1.4 to 2.1$)$ & $<0.001$ \\
\hline Ulcerative colitis $^{3}$ & 32 & 25.2 & 1.3 (0.9 to 1.8$)$ & 0.21 \\
\hline
\end{tabular}

$O$ Observed number of cases, $E$ Expected number, $R R$ Rate ratio, 95\% Cl 95\% Confidence interval.

${ }^{1}$ Hip replacement and knee replacement were excluded from the reference cohort.

${ }^{2}$ Nasal polyp and deflected septum were excluded from the reference cohort. ${ }^{3}$ Hemorrhoids, appendectomy and cholelithiasis were excluded from the reference cohort.

${ }^{4}$ Cataracts were excluded from the reference cohort.

${ }^{5}$ Limb fractures, dislocations, superficial injury, squint and head injury were excluded from the reference cohort.

Diseases studied, but with fewer than five observed cases: dermatomyositis, Goodpasture's syndrome, myasthenia gravis, pemphigus, polyarteritis nodosa. admission for rickets (Table 3). Celiac disease had a substantially increased risk.

There were significantly elevated risks of Addison's disease, celiac disease, diabetes mellitus, Sjogren's syndrome and thyrotoxicosis; and significantly reduced risks for asthma and myxoedema after hospital admission for osteomalacia (Table 4). The rate ratios for Addison's disease, and celiac disease were particularly high. There were significantly elevated rates of Addison's disease, celiac disease, Crohn's disease, diabetes mellitus, pemphigoid, pernicious anemia, primary biliary cirrhosis, rheumatoid arthritis, Sjogren's syndrome, SLE and thyrotoxicosis; and significantly reduced rates for asthma and myxoedema after hospital admission for vitamin D deficiency (Table 5). Again, the rate ratios for Addison's disease and celiac disease were particularly high, as was the rate ratio for SLE.

Unadjusted associations when done, see Methods, are shown in Table 6.

\section{Discussion}

We present evidence associating vitamin D deficiency (or proxies of vitamin D deficiency) with risks of or protection against developing subsequent immune-mediated disease. Previous studies have linked inherited forms of rickets with MS [14] and type 1 diabetes [15], but no study has attempted an analysis similar to the one we present here. Addison's disease and thyrotoxicosis were significantly associated in all analyses, and asthma was significantly low in all but one. The combined analysis found associations with a greater number of immunemediated diseases - a lack of significance in the individual rickets, osteomalacia or vitamin D deficiency cohorts may reflect the lower power of these individual analyses.

The associations described warrant further attention. Mechanistically, it is possible that vitamin D deficiency predisposes to the development of immune-mediated disease by perturbing the immune response [2]. Another explanation is reverse causality - that the disease (either sub-clinically or clinically present but not recorded with a hospital admission prior to the vitamin D deficiency

Table 3 Rate ratios for immune-mediated diseases following admission for rickets

\begin{tabular}{lrrrr}
\hline Disease & O & E & RR (95\% Cl) & P-value \\
\hline Asthma (aged 5 to 54) & 21 & 32.7 & $0.6(0.4$ to 1.0$)$ & 0.05 \\
Celiac disease & 10 & 1 & $10.3(4.9$ to 18.9$)$ & $<0.001$ \\
Myxoedema & 26 & 17.7 & $1.5(1.0$ to 2.2$)$ & 0.06 \\
Pernicious anemia & 6 & 1.6 & $3.7(1.4$ to 8.0$)$ & 0.002 \\
Rheumatoid arthritis & 9 & 5 & $1.8(0.8$ to 3.4$)$ & 0.12 \\
Thyrotoxicosis & 7 & 2.1 & $3.4(1.4$ to 6.9) & 0.002 \\
\hline
\end{tabular}

$O$ Observed number of cases; $E$ Expected number, $R R$ Rate ratio, 95\% Cl 95\% confidence interval. 
Table 4 Rate ratios for immune-mediated diseases following admission for osteomalacia

\begin{tabular}{|c|c|c|c|c|}
\hline Disease & 0 & E & RR $(95 \% \mathrm{Cl})$ & $P$-value \\
\hline Addison's disease & 9 & 1.1 & 8.1 (3.7 to 15.4$)$ & $<0.001$ \\
\hline Ankylosing spondylitis & 5 & 2.9 & $1.7(0.57$ to 4.1$)$ & 0.33 \\
\hline Asthma (aged 5 to 54) & 50 & 71.9 & 0.7 (0.5 to 0.9$)$ & 0.01 \\
\hline Celiac disease & 32 & 4.9 & 6.5 (4.4 to 9.2 ) & $<0.001$ \\
\hline Crohn's disease & 12 & 7.1 & 1.7 (0.9 to 3.0$)$ & 0.10 \\
\hline Diabetes mellitus (aged 0 to 29) & 11 & 3.8 & 2.9 (1.5 to 5.2$)$ & 0.001 \\
\hline Idiopathic thrombocyt. purpura & 5 & 2.9 & $1.8(0.6$ to 4.1$)$ & 0.33 \\
\hline Myxoedema & 143 & 185.8 & $0.8(0.7$ to 0.9$)$ & 0.002 \\
\hline Pernicious anemia & 23 & 15.1 & 1.5 (1.0 to 2.3$)$ & 0.06 \\
\hline Primary biliary cirrhosis & 5 & 1.9 & 2.7 (0.9 to 6.3) & 0.05 \\
\hline Psoriasis & 11 & 14.6 & $0.8(0.4$ to 1.4$)$ & 0.42 \\
\hline Rheumatoid arthritis & 54 & 49.3 & $1.1(0.8$ to 1.4$)$ & 0.55 \\
\hline Sjogren's syndrome & 8 & 3.7 & 2.2 (0.9 to 4.3$)$ & 0.04 \\
\hline Thyrotoxicosis & 30 & 20.8 & $1.4(1.0$ to 2.1$)$ & 0.06 \\
\hline Ulcerative colitis & 11 & 10.7 & $1.0(0.5$ to 1.9$)$ & 0.96 \\
\hline
\end{tabular}

$O$ Observed number of cases, $E$ Expected number, $R R$ Rate ratio, 95\% Cl 95\% confidence interval.

Table 5 Rate ratios for immune-mediated diseases following admission for vitamin D deficiency (coded as such)

\begin{tabular}{|c|c|c|c|c|}
\hline Autoimmune condition & 0 & $\mathrm{E}$ & RR $(95 \% \mathrm{Cl})$ & $P$-value \\
\hline Addison's disease & 12 & 1.7 & 7.0 (3.6 to 12.3$)$ & $<0.001$ \\
\hline Ankylosing spondylitis & 10 & 5.3 & 1.9 (0.9 to 3.5$)$ & 0.06 \\
\hline Asthma (aged 5 to 54 ) & 83 & 278.9 & $0.3(0.2$ to 0.4$)$ & $<0.001$ \\
\hline Celiac disease & 38 & 8.6 & 4.4 (3.1 to 6.1) & $<0.001$ \\
\hline Crohn's disease & 33 & 10 & 3.3 (2.3 to 4.6$)$ & $<0.001$ \\
\hline Diabetes mellitus (aged 0 to 29) & 20 & 6.2 & $3.2(2.0$ to 5.0$)$ & $<0.001$ \\
\hline Idiopathic thrombocyt. purpura & 5 & 5 & $1.0(0.3$ to 2.3$)$ & 0.83 \\
\hline Multiple sclerosis & 12 & 8.2 & 1.5 (0.8 to 2.6$)$ & 0.25 \\
\hline Myxoedema & 177 & 328.2 & 0.5 (0.5 to 0.6$)$ & $<0.001$ \\
\hline Pemphigoid & 10 & 2.7 & 3.7 (1.8 to 6.8$)$ & $<0.001$ \\
\hline Pernicious anemia & 34 & 19.6 & 1.7 (1.2 to 2.4$)$ & 0.002 \\
\hline Primary biliary cirrhosis & 7 & 2.4 & $2.9(1.2$ to 6.0$)$ & 0.008 \\
\hline Psoriasis & 18 & 28.9 & $0.6(0.4$ to 1.0$)$ & 0.05 \\
\hline Rheumatoid arthritis & 101 & 74.5 & $1.4(1.1$ to 1.7$)$ & 0.003 \\
\hline Sjogren's syndrome & 12 & 5.7 & 2.1 (1.1 to 3.7) & 0.01 \\
\hline Systemic lupus erythematosus & 28 & 5.3 & 5.3 (3.5 to 7.7$)$ & $<0.001$ \\
\hline Thyrotoxicosis & 67 & 35.9 & 1.9 (1.5 to 2.4$)$ & $<0.001$ \\
\hline Ulcerative colitis & 21 & 13.6 & 1.5 (0.9 to 2.3$)$ & 0.06 \\
\hline
\end{tabular}

$O$ Observed number of cases, $E$ Expected number, $R R$ Rate ratio, 95\% Cl 95\% confidence interval.
Table 6 Unadjusted* RRs for immune-mediated diseases following admission for rickets, osteomalacia or vitamin D deficiency, combined

\begin{tabular}{lrrrrr}
\hline Autoimmune condition & O & E & RR (95\% Cl) & P-value \\
\hline Ankylosing spondylitis & 16 & 9.3 & $1.73(0.99$ to 2.81$)$ & 0.04 \\
Asthma (aged 5 to 54) & 150 & 393 & $0.38(0.32$ to 0.45$)$ & $<0.001$ \\
Celiac disease & 78 & 15.8 & $4.96(3.91$ to 6.19) & $<0.001$ \\
Crohn's disease & 47 & 23.2 & $2.03(1.49$ to 2.7) & $<0.001$ \\
Diabetes mellitus & 20 & 6.3 & $3.2(1.96$ to 4.95$)$ & $<0.001$ \\
(aged 0 to 29) & & & & \\
Multiple sclerosis & 15 & 16.4 & $0.92(0.51$ to 1.51) & 0.826 \\
Rheumatoid arthritis & 158 & 147.2 & $1.07(0.91$ to 1.25) & 0.397 \\
Ulcerative colitis & 32 & 28.9 & $1.11(0.76$ to 1.56) & 0.626 \\
\hline
\end{tabular}

$O$ Observed number of cases, $E$ Expected number, $R R$ Rate ratio, 95\% Cl 95\% confidence interval.

* See Methods section and legend for Table 2.

admission) reduces vitamin D levels as a result of an inflammatory state and/or causes the individual to spend less time outdoors [16]. The increasing awareness of vitamin D may also lead to an increase in requests for vitamin $\mathrm{D}$ testing, and subsequent diagnosis of vitamin $\mathrm{D}$ deficiency [17]. However, under either of these hypotheses the apparent protective effects of vitamin $\mathrm{D}$ deficiency on asthma and myxoedema are not easy to reconcile. There are reports, however, that state that higher levels of vitamin D in childhood may increase the risk of asthma $[18,19]$. For disorders such as celiac disease there may be an issue with regards to intake and/or malabsorption of vitamin D; with Addison's disease, glucocorticoid deficiency may lead to suppression of the parathyroid hormone-vitamin D axis [20].

The study has limitations. It is not a prospective cohort with follow-up from the date of "first ever" diagnosis, but just from "first recorded" diagnosis in a hospital day case or inpatient record. Data are not recorded on patients who move out of the area covered by data collection or who are treated in hospitals outside the area. The dataset is limited to people who were admitted to hospital, or who received day case specialist care, and thus there exists the potential for selection bias. There is very limited information on potential confounding factors, such as detailed socioeconomic characteristics, ethnicity and smoking. The effect of making multiple comparisons needs to be considered. It is possible that some of the associations that are significant may result from making multiple comparisons and the play of chance. To aid assessment of this, we have provided $P$-values so that readers can judge where $P$-values are extreme: for example, with $P$-values as high as $<0.001$ for the associations between the vitamin $\mathrm{D}$ related conditions, combined, and celiac and Crohn's disease, the associations are unlikely to be chance alone. 


\section{Conclusions}

Our results should be regarded as speculative. Further studies should look at individual immune-mediated diseases in greater depth to confirm or refute the findings and investigate mechanisms behind any association. Regardless of the direction of causality, the fact that individuals with immune-mediated disease are at risk of vitamin $\mathrm{D}$ deficiency is of note to ensure they are made replete to support adequate bone health [2].

\section{Abbreviations}

HES: Hospital episode statistics; ICD: International classification of disease; NHS: National Health Service; OPCS: Office of population, censuses and surveys; SLE: Systemic lupus erythematosus.

\section{Competing interests}

The authors declared that they have no competing interest.

\section{Authors' contributions}

MJG is the guarantor and designer of the study. RG undertook the analysis. SVR and MJG contributed to the analysis and interpretation of the data. SVR wrote the first draft and all authors contributed to subsequent drafts and the final paper.

\section{Acknowledgements}

This Unit of Health-Care Epidemiology and its work on record linkage are funded by the English National Institute for Health Research. The study sponsors had no role in the design and conduct of the study; collection, management, analysis, and interpretation of the data; and preparation, review, or approval of the manuscript. All authors state that this research was carried out independently of the influence of funding bodies.

\section{Author details}

'Department of Physiology, Anatomy and Genetics and Medical Research Council Functional Genomics Unit, University of Oxford, Oxford, UK. ${ }^{2}$ Blizard Institute, Barts and the London School of Medicine and Dentistry, Queen Mary University of London, London, UK. ${ }^{3}$ Unit of Health-Care Epidemiology, Nuffield Department of Population Health, University of Oxford, Oxford, UK.

Received: 13 May 2013 Accepted: 5 July 2013

Published: 25 July 2013

\section{References}

1. Shapira Y, Agmon-Levin N, Shoenfeld Y: Defining and analyzing geoepidemiology and human autoimmunity. J Autoimmun 2010, 34:J168-J177.

2. Holick MF: Vitamin D deficiency. N Engl J Med 2007, 357:266-281.

3. Cantorna MT: Vitamin D and autoimmunity: is vitamin D status an environmental factor affecting autoimmune disease prevalence? Proc Soc Exp Biol Med 2000, 223:230-233.

4. Cutolo M, Otsa K, Paolino S, Yprus M, Veldi T, Seriolo B: Vitamin D involvement in rheumatoid arthritis and systemic lupus erythaematosus. Ann Rheum Dis 2009, 68:446-447.

5. Kamen DL, Tangpricha V: Vitamin D and molecular actions on the immune system: modulation of innate and autoimmunity. $J \mathrm{Mol}$ Med (Berl) 2010, 88:441-450.

6. White $\mathrm{JH}$ : Vitamin $\mathrm{D}$ metabolism and signaling in the immune system. Rev Endocr Metab Disord 2012, 13:21-29.

7. Munger KL, Levin LI, Hollis BW, Howard NS, Ascherio A: Serum 25-hydroxyvitamin D levels and risk of multiple sclerosis. JAMA 2006, 296:2832-2838.

8. Littorin B, Blom P, Schölin A, Arnqvist HJ, Blohmé G, Bolinder J, Ekbom-Schnell A, Eriksson JW, Gudbjörnsdottir S, Nyström L, Ostman J, Sundkvist G: Lower levels of plasma 25-hydroxyvitamin D among young adults at diagnosis of autoimmune type 1 diabetes compared with control subjects: results from the nationwide Diabetes Incidence Study in Sweden (DISS). Diabetologia 2006, 49:2847-2852.

9. Amital H, Szekanecz Z, Szücs G, Dankó K, Nagy E, Csépány T, Kiss E, Rovensky J, Tuchynova A, Kozakova D, Doria A, Corocher N, Agmon-Levin N,
Barak V, Orbach H, Zandman-Goddard G, Shoenfeld Y: Serum concentrations of $25-\mathrm{OH}$ vitamin $\mathrm{D}$ in patients with systemic lupus erythematosus (SLE) are inversely related to disease activity: is it time to routinely supplement patients with SLE with vitamin D? Ann Rheum Dis 2010, 69:1155-1157.

10. Kerr GS, Sabahi I, Richards JS, Caplan L, Cannon GW, Reimold A, Thiele GM, Johnson D, Mikuls TR: Prevalence of vitamin D insufficiency/deficiency in rheumatoid arthritis and associations with disease severity and activity. J Rheumatol 2011, 38:53-59.

11. Gama R, Waldron JL, Ashby HL, Cornes MP, Bechervaise J, Razavi C, Thomas OL, Chugh S, Deshpande S, Ford C: Hypovitaminosis D and disease: consequence rather than cause? BMJ 2012, 345:e5706-e5706.

12. Ramagopalan SV, Wotton CJ, Handel AE, Yeates D, Goldacre MJ: Risk of venous thromboembolism in people admitted to hospital with selected immune-mediated diseases: record-linkage study. BMC Med 2011, 9:1.

13. Breslow NE, Day NE: Statistical methods in cancer research. Volume II - The design and analysis of cohort studies. IARC Sci Publ 1987:1-406.

14. Torkildsen $\varnothing$, Knappskog PM, Nyland HI, Myhr K-M: Vitamin D-dependent rickets as a possible risk factor for multiple sclerosis. Arch Neurol 2008, 65:809-811.

15. Nguyen M, d'Alesio A, Pascussi JM, Kumar R, Griffin MD, Dong X, Guillozo H, Rizk-Rabin $M$, Sinding $C$, Bougnères $P$, Jehan F, Garabédian M: Vitamin D-resistant rickets and type 1 diabetes in a child with compound heterozygous mutations of the vitamin D receptor (L263R and R391S): dissociated responses of the CYP-24 and rel-B promoters to 1,25-dihydroxyvitamin D3. J Bone Miner Res 2006, 21:886-894.

16. Harvey NC, Cooper C: Vitamin D: some perspective please. BMJ 2012, 345:e4695-e4695.

17. Sattar N, Welsh P, Panarelli M, Forouhi NG: Increasing requests for vitamin D measurement: costly, confusing, and without credibility. Lancet 2012, 379:95-96.

18. Tolppanen A-M, Sayers A, Granell R, Fraser WD, Henderson J, Lawlor DA: Prospective association of 25-hydroxyvitamin $\mathrm{d} 3$ and $\mathrm{d} 2$ with childhood lung function, asthma, wheezing, and flexural dermatitis. Epidemiology 2013, 24:310-319.

19. Hyppönen E, Sovio U, Wjst M, Patel S, Pekkanen J, Hartikainen AL, Järvelinb MR: Infant vitamin D supplementation and allergic conditions in adulthood: northern Finland birth cohort 1966. Ann N Y Acad Sci 2004, 1037:84-95.

20. Montoli A, Colussi G, Minetti L: Hypercalcaemia in Addison's disease: calciotropic hormone profile and bone histology. J Intern Med 1992, 232:535-540.

doi:10.1186/1741-7015-11-171

Cite this article as: Ramagopalan et al:: Hospital admissions for vitamin $D$ related conditions and subsequent immune-mediated disease: record-linkage studies. BMC Medicine 2013 11:171.

\section{Submit your next manuscript to BioMed Central and take full advantage of:}

- Convenient online submission

- Thorough peer review

- No space constraints or color figure charges

- Immediate publication on acceptance

- Inclusion in PubMed, CAS, Scopus and Google Scholar

- Research which is freely available for redistribution 